\title{
Traffic Simulation of Hongqi Elevated Road in Yantai
}

\author{
Feng Zhu ${ }^{\mathrm{a}}$, Chengxuan $\mathrm{Cao}^{\mathrm{b}}$ \\ State Key Laboratory of Rail Traffic Control and Safety \\ Beijing Jiaotong University, Beijing 100044, China. \\ a15125815@bjtu.edu.cn, ${ }^{\mathrm{b}} \mathrm{cxcao@bjtu.edu.cn}$
}

Keywords: Traffic simulation, Hongqi Elevated Road, VISSIM.

Abstract. With the increasing number of vehicles in Yantai, the downtown traffic volume is increasing. Hongqi Road, the main road in Yantai exists the traffic congestion problems. Yantai Planning Bureau proposed to construct for viaduct this road. This design is mainly based on the planning and design of the elevated road in Yantai Hongqi Road (Hongqi Road intersection-Shanhai Road intersection). We used the VISSIM micro simulation system to carry out the simulation of the elevated road in Hongqi Road, and the stops and queue length are the evaluation indices for quantitative evaluation. Then through the evaluation indices and specific data obtained by simulation, we analyze the selection of the scheme and draw the final plan of the construction of the elevated road, which was provide a good reference for the planning and construction of Hongqi elevated road.

\section{Introduction}

The emergence of the viaduct is a very important detail in the course of the evolution of the city. It reflects the city's increasingly crowded trends and the city's displacement in space form (from a horizontal plane to a vertical section) [1]. After Hongqi elevated road built, this east-west freeway will remain basically smooth all the way, this will further widen the urban framework, improve the speed of vehicle driving and the traffic capacity of Hongqi road, guarantee the none-congestion of the backbone, increase the efficiency of the green time and reduce the traffic delay. Moreover, it can greatly ease traffic in the downtown of Yantai and improve the safety factor of residents' trip.

\section{Analysis on traffic operation problems of Hongqi Road}

Hongqi Road is an important traffic hub that connects High-tech Zone, Laishan District, Zhifu District, Development District and east-west direction of Fushan District in Yantai. Hongqi Middle Road is the traffic bottleneck of them, its traffic conditions directly related to the South Street and the North Road in the downtown area. Hongqi Road-Shanhai Road junction is located in the periphery of the central district. It is a main traffic hinge junction in north-east direction of the city, close to the Experimental Middle School, Qishan Community and some other old residential areas. Therefore, this area is both the starting point and the passing point. East entrance is connected to west entrance of Kuixinglou Tunnel [2].The traffic is heavy during morning and evening rush hours, so the traffic conditions is very complicated. The intersection's screenshot is shown in Fig. 1.

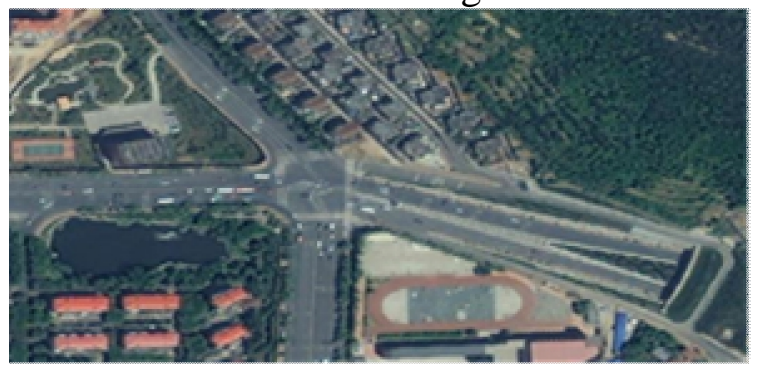

Fig. 1 The Hongqi Road - Shanhai Road intersection satellite image 


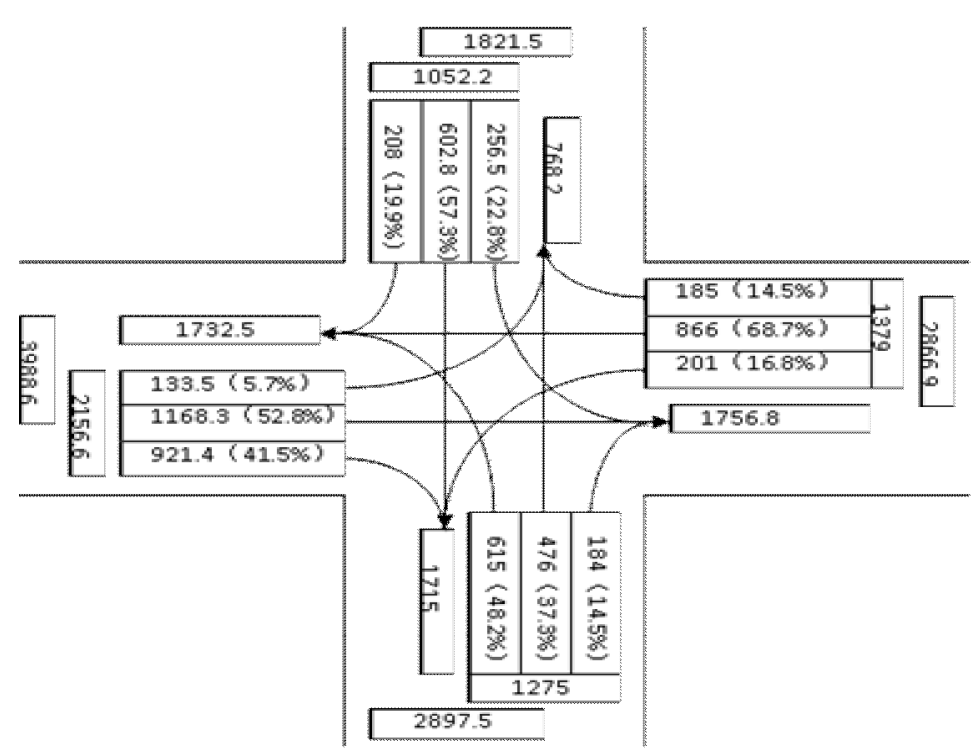

Fig. 2 Morning rush hour (7:30-8:30) traffic flow diagram

\section{The traffic flow diagram is shown in Fig. 2.}

Peak Hour selection. Determination of Peak hours is the premise of the intersection simulation, we chose the morning-peak-hour traffic volume to simulate is the most effective solution.

Intersection Traffic Flow Analysis. As it can be seen from Fig. 2, the traffic volume of East-West entrance is large during morning rush hour, especially the west entrance. The south entrance volume is slightly larger than the north entrance.

Queue Length Analysis. East and West Entrance queue length is larger than other entrances, which extends to the outside of the Kuixinglou Tunnel and the west of Qishan East Road.

Saturation analysis. In order to investigate the severity of congestion in this intersection, we calculate the saturation of each entrance on the basis of the distribution of traffic on the intersection. As shown in Table1.

Table 1 Saturation analysis table

\begin{tabular}{cccc}
\hline Direction & $\begin{array}{c}\text { Traffic capacity } \\
(\text { PCU })\end{array}$ & $\begin{array}{c}\text { Traffic volume } \\
(\text { PCU })\end{array}$ & $\begin{array}{c}\text { Proportion } \\
\text { V/C }\end{array}$ \\
\hline East entrance & 1582 & 1379 & 0.87 \\
West entrance & 2672 & 2157 & 0.81 \\
South entrance & 875 & 1275 & 1.46 \\
North entrance & 805 & 1052 & 1.31 \\
Intersection & 5934 & 5863 & 0.99 \\
\hline
\end{tabular}

As it can be seen from Table 1, in the current signal timing, the load degree of the north entrance and south entrance is large, the corresponding load degree can reach 1.46 and 1.31 respectively; overall saturation of Intersections is 0.99 , tends to the critical value 1 . This is mainly due to the traffic capacity of this entrance does not match the situation and the steering traffic volume is large.

\section{The scheme design of Hongqi elevated road}

In this scheme, the viaduct is designed from the west exit of Kuixinglou Tunnel to the east entrance of Nanshan Tunnel. The straight-going traffic of Hongqi elevated road linked with the ground on the west side of Kuixinglou Tunnel and the east side of Nanshan Tunnel respectively. Three intersections along this main line will also be set up on-ramp and off-ramp. As an important point in this design, the connection problems of the viaduct and ground in Hongqi Road-Shanhai Road intersection is the key point of the design $[3,4]$. And the schematic diagram is shown in Fig. 3. 


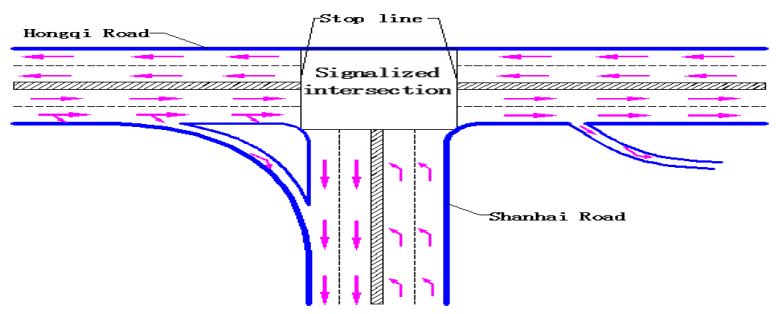

Fig. 3 The Schematic diagram

Traffic flow analysis. As it can be seen from Fig. 3, as the principal east-west corridors-Hongqi Road in this scheme, the traffic flow in the East and West is only allowed to go straight and turn right. Hongqi elevated road has the bi-directional and four lanes, the direct vehicles which are come from East entrance and West entrance can cross the intersection from the viaduct smoothly, the left-turn vehicles which are come from West entrance in Hongqi Road can pass the intersection under the viaduct. The east exit of Hongqi Road is located on the exit ramp of the elevated road, which is connected with the outer lane of the Huanshan Road. The traffic flow from Hongqi elevated road and the right-turn vehicles from Shanhai Road go into the Kuixinglou Tunnel together. Moreover, the left-turn vehicles from Shanhai Road can cross the intersection from the viaduct. In totally, the Hongqi elevated road program will greatly improve the traffic capacity of Hongqi Road [5, 6].

VISSIM simulation. We collect the data through the video camera at this intersection, at the same time there are artificial data collection in our survey. Through the data analysis, we chose the peak hours. Regional traffic problems mainly exist in the peak hours. Therefore, all of the following simulations are carried out on the peak hours (7:30-8:30) of the traffic conditions. The intersection Traffic Light Control System is divided into 5 phases, the cycle is 121s. The traffic operation of the intersection during the morning and evening rush hours is basically good, the intersection from the point of view of the optimization of the signal is very small, but there is still room for optimization of the north-south entrance. Finally, we evaluate the advantages and disadvantages of the scheme through simulation output indices, and confirm the optimum scheme finally [7]. The simulation screenshot is shown in Fig. 4.

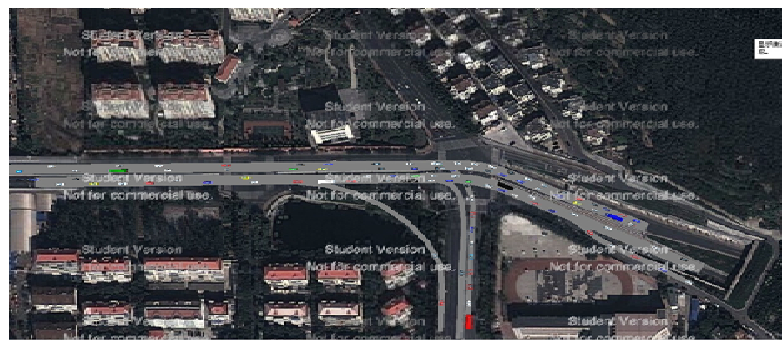

Fig. 4 Simulation 3D interface diagram on the viaduct

Simulation Evaluation and impact assessment. Through the Traffic Network Simulation and Parameters Calibration, we finally output a variety of simulation evaluation indices. As shown in Table 2.

Table 2 Evaluation indices comparing

\begin{tabular}{cccccc}
\hline $\begin{array}{c}\text { Evaluation } \\
\text { index }\end{array}$ & $\begin{array}{c}\text { Stop delay } \\
(\mathrm{s})\end{array}$ & $\begin{array}{c}\text { Stops } \\
\text { ( frequency })\end{array}$ & $\begin{array}{c}\text { Queue length } \\
(\mathrm{m})\end{array}$ & $\begin{array}{c}\text { Traffic volume } \\
(\mathrm{PCU})\end{array}$ & $\begin{array}{c}\text { Fuel consumption } \\
(\mathrm{l})\end{array}$ \\
\hline Intersection status & 32.7 & 0.88 & 177.6 & 5863 & 404.15 \\
Timing change & 32.5 & 0.82 & 159.4 & 5890 & 399.40 \\
Percentage & $0.61 \%$ & $6.82 \%$ & $10.2 \%$ & $0.05 \%$ & $1.18 \%$ \\
\hline
\end{tabular}

Through the Traffic Network Simulation and Parameters Calibration, we finally output a variety of simulation evaluation indices. As shown in Table 2, the queue length in East-West direction is 177.6 meters. And the simulation results show that the queue length in East-West direction is 159.4 meters, the vehicle queue length has been reduced. Since the signal timing scheme is implemented, this program has a greater margin of improvement to social vehicles. The stop delay time is $32.7 \mathrm{~s}$, which is slightly 
different from the current simulation. And the error is within the calibration range, so the simulation results are in agreement with the actual situation. The number of shutdown times is 0.88 , which is slightly different from the current simulation. And the error is within the calibration range, so the simulation results are in agreement with the actual situation. After the signal timing optimization scheme, the number of stops is lower than before. The error of current traffic condition is in the calibration range, and the simulation results are consistent with the current situation. The fuel consumption index is greatly reduced, and the traffic volume and fuel consumption ratio of the project are lower than before.

The output simulation data are based in good conditions, all kinds of vehicles compliance and law-abiding, no traffic accidents and other comprehensive traffic conditions are good. While in the actual traffic process, due to the influence of various realistic traffic factors and simulation errors, there is a certain discrepancy.

\section{Conclusions}

In this paper, the improvement of principal east-west corridors in Yantai is studied. The proposed scheme can improve the traffic capacity of Hongqi Road effectively, which provides a reference for solving the traffic problems based on VISSIM Simulation Platform. Moreover, in view of the traffic situation of Yantai, we carried out a research on the road and the intersection of the Hongqi Road, which has certain practical reference value to improve the traffic problems and ease the traffic congestion in Yantai.

\section{Acknowledgements}

This research was supported by the Research Foundation of State Key Laboratory of Rail Traffic Control and Safety, Beijing Jiaotong University, China (Grant No. RCS2016ZZ001 and RCS2015ZZ003).

\section{References}

[1] Zhou Liang. City viaduct design and construction technology. China Building Industry Press (2010), p. 1-15. (In Chinese)

[2] Information on http://yantai.dzwww.com/xinwen/ytxw/ytsh/201312/t20131217_9360151.htm.

[3] Zhang Yuhua. Road-related survey and design. Beijing: China communication press (1997), p. 262-303. (In Chinese)

[4] You Xiaohui, Shen Xiaohui. Modern road survey design. Beijing: Tsinghua University press, Beijing Jiaotong University press (2009), p. 295-330. (In Chinese)

[5] A. D. May, Traffic Flow Fundamentals. Prentice Hall (1990), p. 62-100. (In Chinese)

[6] Li Li, Jiang Rui, Jia Bin, Zhao Xiaomei. Modern traffic flow theory and Application. Beijing: Tsinghua university press (2011), p. 155-198. (In Chinese)

[7] Liu Bohang, Zhang Tong, An Guijiang, Li Keping. Traffic simulation experiment course. Beijing: Beijing: China communication press (2012), p, 125-168. (In Chinese) 